\title{
Reflexão e Análise da Formação de Educadores de Jovens e Adultos do Campo
}

\author{
Katia Pinheiro Freitas \\ Lourdes Helena da Silva' \\ 'Universidade Federal de Viçosa (UFV), Viçosa/MG - Brasil
}

RESUMO - Reflexão e Análise da Formação de Educadores de Jovens e Adultos do Campo. Neste artigo abordamos os desafios da EJA do Campo na formação dos seus educadores, a partir de uma revisão da produção acadêmica nacional do período de 2006 a 2011. Os dados, obtidos junto ao Banco de Teses da CAPES e Instituições do Ensino Superior de Minas Gerais, foram analisados conjugando contribuições teóricas da Educação de Jovens e Adultos, Educação do Campo e Formação de Professores. Nossos resultados revelam, entre outros, uma tendência das experiências de EJA do Campo se desenvolverem por meio de programas e/ou projetos, envolvendo parcerias diversas, com destaque para o envolvimento dos movimentos sociais nos processos de formação dos educadores. Revelam, ainda, a necessidade de investimentos na formação específica dos educadores - formação inicial e continuada, a partir de processos que contribuam para uma melhor compreensão dos aportes teórico-metodológicos dessa modalidade de ensino. Palavras-chave: Educação do Campo. Educação de Jovens e Adultos. Formação de Educadores.

ABSTRACT - Reflection and Analysis of the Training of Education Professionals for Rural Youngsters and Adults. The present article addresses the challenges of training teachers for rural youngsters and adults, based on a review of the national academic literature produced from 2006 to 2011. The data, obtained from the CAPES Clearing House of Dissertations and Higher Education Institutions of Minas Gerais state, were analyzed according to the combination of the theoretical contributions from Rural Youth and Adult Education, Rural Education and Teacher Training literature. Our results reveal, among other issues, that education for rural adults and youth tends to be developed through programs and/or projects and several partnerships, particularly the involvement of social movements in the teacher training process. They also reveal the need for investment in specific teacher training - initial and continued training, based on processes that enhance the understanding of the theoretical and methodological contributions of this mode of education.

Keywords: Rural Education. Youth and Adult Education. Teacher Training.

Educação \& Realidade, Porto Alegre, v. 41, n. 2, p. 555-573, abr./jun. 2016. 555 http://dx.doi.org/10.1590/2175-623647950 
Reflexão e Análise da Formação de Educadores de Jovens e Adultos do Campo

\section{Introdução}

O campo no Brasil encontra-se em movimento, com seus sujeitos sociais se alinhando em lutas e mobilizações diversas. Uma dessas mobilizações é em defesa de uma educação específica e de qualidade que, afirmando o campo como território de vida e de sobrevivência, busca desenvolver processos e práticas educativas de uma formação mais ampla e significativa para os povos do campo (Molina, 2010).

É nesse contexto que a Educação do Campo - um movimento nacional de resistência às investidas do capitalismo no campo e à sua lógica de exclusão dos sujeitos que vivem nesse território - tem conquistado espaço na agenda política nacional. Enquanto movimento e teoria em construção, a Educação do Campo reconhece o campo e a diversidade de seus sujeitos sociais e coletivos, com seus próprios modos de vida, de organização do trabalho e do espaço geográfico, suas organizações políticas, suas identidades, manifestações culturais e seus conflitos (Fernandes, 2008; Molina, 2010). É, portanto, um movimento nacional que prioriza os sujeitos do campo e os impulsiona a construir uma identidade própria de homem do campo, de educação e de escola.

Apesar de uma trajetória de 17 anos em nossa sociedade e de um conjunto de conquistas e avanços realizados neste período, o movimento da Educação do Campo ainda enfrenta diversos desafios e demandas sociais históricas na consolidação do seu projeto político pedagógico de construção de uma educação e de uma escola do campo. Um desses desafios, conforme destacam Arroyo (2007) e Souza (2008), é a formação específica dos educadores do campo. E esse é um desafio que se torna ainda maior quando a referência é a formação de educadores para uma atuação específica na Educação de Jovens e Adultos (EJA) do campo.

No presente trabalho - oriundo de uma pesquisa que analisou os avanços, limites e perspectivas da formação dos educadores de jovens e adultos do campo, buscamos sistematizar um conjunto de reflexões e analises sobre a EJA do Campo e a formação dos seus educadores. Na realização desses propósitos, o artigo foi estruturado em três blocos: inicialmente, desenvolvemos uma aproximação teórica entre as temáticas de Educação de Jovens e Adultos e Educação do Campo; na sequência, realizamos uma análise da produção acadêmica nacional, identificando suas contribuições para uma compreensão sobre as especificidades das experiências de EJA do Campo e dos processos de formação de seus educadores. Finalizando, em nossas considerações, analisamos os desafios e perspectivas enfrentados pela EJA do Campo para a formação de seus educadores.

\section{Educação de Jovens e Adultos e Educação do Campo: aproximações teóricas}

Uma revisão da literatura sobre a Educação de Jovens e Adultos na sociedade brasileira nos coloca, inevitavelmente, frente a uma história 
marcada por contínua e sistemática usurpação do direito dos jovens e adultos brasileiros de acesso e de permanência na escola. Estudos como o de Fazzi (2007), Di Pierro (2010), Moura (2009) e Porcaro (2011) revelam múltiplos aspectos desta ausência histórica de políticas e de ações governamentais em nossa sociedade, em favor da garantia dos jovens e adultos ao direito à educação. Estes estudos também destacam que a EJA tem sido tratada, no discurso governamental, como uma modalidade de educação temporária, tornando-se cada vez mais alinhada às políticas neoliberais de contenção dos gastos públicos com as questões sociais. Aliado a isto, os estudos também evidenciam que a formação de educadores para uma atuação na realidade da EJA não tem sido uma prioridade, visto a ausência de instituições formadoras e de políticas públicas orientadas para uma formação específica de seus educadores. Temos, assim, um cenário marcado por dívidas, lacunas e silenciamentos diversos que, no conjunto, contribuem para que o ensino destinado aos jovens e adultos no Brasil se configure muito mais como um transplante de concepções, estrutura e funcionamento do ensino regular, tornando a maioria dos cursos de EJA um espaço de um ensino pouco atrativo, com conteúdos, práticas e processos divorciados da vida e dos interesses dos educandos.

Todavia, frente a esse quadro histórico de ausência de políticas públicas de formação de educadores de jovens e adultos têm ocorrido, diversas mobilizações da sociedade civil, em diferentes regiões brasileiras, por meio dos Fóruns de EJA, que tem contribuído para fomentar o debate e demandar ações mais efetivas das esferas governamentais. Também nessa perspectiva de organização popular, têm ocorrido em nossa sociedade diversas ações dos movimentos sociais e sindicais do campo, de mobilização e de lutas por políticas públicas de garantia aos sujeitos do campo ao direito à educação (Arroyo; Caldart; Molina, 2004).

Na especificidade deste movimento de construção da educação e da escola do campo, a formação de educadores tem sido uma de suas prioridades, especialmente no âmbito do Movimento dos Trabalhadores Sem Terra (MST) que, afirmando-a como direito dos educadores e dever do Estado, tem contribuído efetivamente para as conquistas e avanços da Educação do Campo ao longo de sua trajetória histórica em nossa sociedade. Neste processo, conforme ressalta Molina (2010), a organização e luta dos sujeitos do campo em busca do acesso ao conhecimento e à escolarização constitui uma estratégia de resistência à expropriação capitalista no campo.

É importante destacar que a proposta de formação do MST é de uma formação política, orientada para o fortalecimento da identidade dos camponeses e para sua atuação na realidade específica do campo. Como um movimento histórico, cultural e político, o Movimento dos Trabalhadores Sem Terra luta por mudanças na sociedade que ultrapassam a reforma agrária. Assim, o direito à educação é fator essencial que se articula às reivindicações por terra, produção e comercialização no campo (Molina, 2010; Vargas; Manggini, 2007). 
Reflexão e Análise da Formação de Educadores de Jovens e Adultos do Campo

Sob essa lógica, o processo educativo é concebido pelo MST como sendo indissociável das questões políticas enfrentadas na luta pela Reforma Agrária, assumindo uma intencionalidade de sua contribuição para a transformação social e emancipação dos sujeitos jovens e adultos do campo. A educação cumpre, assim, o papel de formação dos jovens e adultos do campo para uma compreensão crítica das conjunturas históricas e políticas da sociedade, fornecendo as bases teóricas que possam contribuir para a implementação das transformações sociais necessárias.

A Educação de Jovens e Adultos assume, portanto, o compromisso de contribuir para a construção de uma visão crítica do educando, desenvolvendo processos de formação orientados para o conjunto das transformações sociais propostas pelo Movimento. Nessa dinâmica, o educador tem um papel fundamental no qual, em conjunto com os educandos e os demais sujeitos envolvidos nas lutas pelas transformações sociais, torna-se capaz de estimular e coordenar processos educativos e de construção coletiva do conhecimento. Sob essa lógica, a formação dos educadores para uma atuação com jovens e adultos do campo tem sido um desafio enfrentado não apenas pelo MST, mas também por outros movimentos do campo e pelas universidades parceiras que, na busca de implementar práticas de formação diferentes dos modelos convencionais, buscam afirmar outras lógicas de formação, como "[...] a lógica da Terra, a lógica do Campo e, sobretudo, a dos sujeitos que ali vivem, constroem e defendem seu modus vivendi" (Antunes-Rocha; Martins, 2009, p. 17).

O enfrentamento destes desafios pelos movimentos sociais e sindicais do campo tem possibilitado a emergência e o desenvolvimento de diversas experiências originais de formação de educadores, em diferentes níveis de ensino, a exemplo dos cursos de Pedagogia da Terra, Magistério e Licenciatura em Educação do Campo, entre outros. Realizados a partir de convênios e parcerias entre os movimentos sociais e sindicais do campo, Governo Federal e universidades públicas brasileiras, são cursos que, de maneira geral, buscam formar educadores a partir dos princípios da Educação do Campo, de valorização da terra, do campo e dos modos de vida dos sujeitos que nele vivem e trabalham. Acrescente-se, ainda, que a inserção destes cursos em universidades públicas com trajetórias consolidadas na formação de educadores, também tem possibilitado aos movimentos reivindicar que as especificidades do campo sejam contempladas nas propostas de currículos e das práticas metodológicas dos processos formativos (Antunes-Rocha; Martins, 2009; Arroyo, 2007) exigindo, assim, que o Estado assuma suas responsabilidades com a formação específica dos educadores do campo. Os movimentos buscam, dessa maneira, fazerem-se presentes “[...] não para receber a mesma formação, mas uma formação específica para trabalhar no campo" (Arroyo, 2007, p. 164).

558 Educação \& Realidade, Porto Alegre, v. 41, n. 2, p. 555-573, abr./jun. 2016. 
No conjunto das experiências construídas no âmbito do movimento da Educação do Campo, o Programa Nacional de Educação na Reforma Agrária (PRONERA) destaca-se como sendo o programa pioneiro na implementação dos princípios de formação de educadores do campo. Criado com o objetivo contribuir para a melhoria da realidade educacional em áreas de reforma agrária no país, o PRONERA constitui uma experiência educativa de parceria efetiva entre movimentos sociais e sindicais do campo, universidades públicas e Governo Federal, no desenvolvimento de ações voltadas à alfabetização de jovens e adultos, ensino fundamental, ensino profissionalizante, ensino superior e formação inicial e continuada dos educadores do campo (Santos, 2008; Batista, 2007).

Analisando o PRONERA enquanto política pública, Munarim (2007) afirma que uma das marcas importantes do Programa foi a sua origem na mobilização de movimentos sociais e sindicais do campo que, como representantes da sociedade civil, encontram-se organizados fora da esfera do Estado. Esta condição de origem contribui para que o Programa se constitua em importante laboratório de alternativas pedagógicas, tornando-se uma referência importante para os processos de construção de políticas públicas na Educação do Campo. Ainda na avaliação de Munarim (2007), a atuação do PRONERA tem se expandido na sociedade brasileira, formando uma espécie de rede própria de educação escolar que, fundamentada na luta pela reforma agrária, tem promovido um casamento da Educação Popular com a Educação Escolar. Assim, articulando essas duas formas históricas de educação, o PRONERA representaria “[...] a concretização de uma dimensão conscientizadora da escola rural. De certa maneira, se estaria vivenciando a efetivação da 'Pedagogia do Oprimido', de Paulo Freire” (Munarim, 2007, p. 11).

Analisando particularmente os processos pedagógicos e as dinâmicas educativas gestadas no interior do PRONERA, Silva, Costa e Rosa (2011) destacam a originalidade e a inovação dos procedimentos metodológicos do Programa que, incorporando concepções e práticas oriundas dos movimentos sociais e sindicais, tem como princípios norteadores a gestão compartilhada, o trabalho coletivo como elemento central, o conhecimento das tensões e contradições próprias da disputa entre o capital e os projetos de educação democrática, e a compreensão da relação entre território, terra, trabalho e escola.

Assim, sob inspiração direta e/ou indireta do PRONERA, diversos cursos de Licenciatura em Educação do Campo têm sido criados nos últimos anos, em diferentes universidades públicas brasileiras, constituindo cada um deles uma conquista importante na consolidação da educação e da escola do campo. São experiências educativas inovadoras na formação de educadores do campo que também têm favorecido processos de aprendizagens diversos para os sujeitos envolvidos na sua 
Reflexão e Análise da Formação de Educadores de Jovens e Adultos do Campo

realização - movimentos sociais e sindicais, sujeitos da luta pela terra, universidades, professores e estudantes.

Em Minas Gerais, uma das ações do PRONERA na formação de educadores para uma atuação específica no campo tem sido desenvolvida pela Faculdade de Educação da Universidade Federal de Minas Gerais, com o curso de Licenciatura em Educação do Campo. Segundo Antunes-Rocha e Martins (2009), este curso surgiu da necessidade de uma formação mais ampliada dos profissionais das escolas do campo, tendo em vista a responsabilidade que eles assumem na condução de uma diversidade de ações educativas específicas do contexto da educação rural. Analisando esse e outros cursos de formação de educadores do campo, Menezes Neto (2009) afirma que eles representam uma conquista de direitos e de possibilidades de construção de uma educação democrática e emancipatória dos sujeitos do campo. Além disso, segundo o autor, as parcerias construídas entre os movimentos e as universidades na implementação desses cursos e na busca de caminhos próprios para uma educação emancipatória “[...] devem ser vistas como uma nova perspectiva de educação e de escola que se inscrevem na construção de uma nova hegemonia pedagógica e social” (Menezes Neto, 2009, p. 37).

Outra experiência de formação de educadores que também se destaca em Minas Gerais, especificamente na formação de educadores de EJA do Campo, é o Projeto Educação, Campo e Consciência Cidadã. Desenvolvido no âmbito do PRONERA, no período de 2001 a 2011, esse projeto foi realizado por uma parceria entre a Universidade do Estado de Minas Gerais, Universidade Federal de Viçosa, Faculdade de Filosofia e Letras de Diamantina, Federação dos Trabalhadores na Agricultura do Estado de Minas Gerais, Movimento dos Trabalhadores Sem Terra e o Instituto Nacional de Colonização e Reforma Agrária. Seu propósito foi promover a formação de educadores de EJA e a alfabetização e escolarização de jovens e adultos dos assentamentos e acampamentos da Reforma Agrária em diferentes regiões de Minas Gerais.

Analisando os processos e as práticas pedagógicas do Projeto Educação, Campo e Consciência Cidadã na formação dos educadores de EJA do campo, Silva, Costa e Rosa (2011) destacam que uma das características marcantes desta experiência educativa foi o forte envolvimento e participação dos parceiros na dinâmica de cogestão e nos processos de construção coletiva de conhecimentos ao longo de sua realização. Outra característica é a originalidade da metodologia utilizada pelo Projeto, que conjugava diferentes espaços e tempos pedagógicos na formação dos educadores de EJA do Campo. Neste aspecto, os Ciclos Estaduais de Formação, as Oficinas Regionais e as Visitas de Acompanhamento às Salas de Aula constituíram as estratégias metodológicas que, utilizadas de maneira articulada, eram orientadas pelo princípio comum de uma formação “[...] colada ao chão da vida” (Silva; Costa; Rosa, 2011, p. 155). Assim, sob inspiração direta dos pressupostos Freirianos, buscava-se o 
desenvolvimento de processos e práticas de formação de educadores de EJA do Campo que, articulados aos processos de existência material e social dos educandos, fosse capaz de afirmar uma perspectiva de educação para a emancipação. Dentre os impactos e conquistas do Projeto Educação, Campo e Consciência Cidadã, as autoras também destacam os aprendizados acumulados ao longo desta experiência educativa de formação de educadores de EJA do campo, principalmente aqueles decorrentes da aliança construída entre universidades e movimentos sociais e sindicais do campo, assim como os reflexos desta parceria no interior das universidades envolvidas no Projeto.

Essa dimensão da parceria entre universidades, movimentos sociais e sindicais do campo e poder público tem sido, na atualidade educacional brasileira, objeto de reflexões e debates diversos. Também o debate em torno da Educação do Campo e de sua inserção na agenda política nacional tem ampliado bastante nos últimos anos, contribuindo para um aumento significativo dos estudos e produções acadêmicas sobre a temática, particularmente na perspectiva da formação de educadores do campo. Todavia, apesar destes e de outros avanços conquistados pelo movimento da Educação do Campo, estudos sobre a formação de educadores, na especificidade da EJA do Campo, ainda são incipientes na produção acadêmica nacional. Quais experiências de EJA estão presentes no campo brasileiro? Quem são os sujeitos dessas experiências educativas? O que essas experiências evidenciam em termos de contradições, desafios e possibilidades para a EJA do Campo e para a formação de seus educadores? Na busca de responder estas e outras questões sobre a EJA do campo, particularmente a identificação dos desafios e perspectivas colocadas para a formação de seus educadores, realizamos um mapeamento e análise da produção acadêmica nacional sobre a EJA do Campo, no período de 2006 a 2011.

\section{Formação de Educadores de EJA do Campo: uma análise da produção acadêmica nacional}

Visando analisar a produção acadêmica do período de 2006 a 2011 sobre a formação dos educadores de jovens e adultos do campo no Brasil, especialmente em Minas Gerais, inicialmente realizamos uma consulta ao Banco de Teses da CAPES. Especificamente nossos propósitos foram mapear os estudos realizados em nossa sociedade sobre a EJA do Campo e a formação de seus educadores, de maneira a identificar e analisar os indícios apresentados pelas pesquisas sobre os avanços, limites e perspectivas da EJA do Campo.

Na consulta ao Banco de Teses da CAPES, utilizando como palavra-chave Educação de Jovens e Adultos, identificamos um total de 935 trabalhos acadêmicos, sendo que especificamente sobre a temática EJA do Campo foram localizados 57 trabalhos, produzidos em diferentes áreas de conhecimento, como Educação, Geografia, Sociologia Política,

Educação \& Realidade, Porto Alegre, v. 41, n. 2, p. 555-573, abr./jun. 2016. 561 
Reflexão e Análise da Formação de Educadores de Jovens e Adultos do Campo

Extensão Rural e Agriculturas Amazônicas. Tendo em vista as especificidades e abrangência do conjunto desses trabalhos, assim como os propósitos da nossa pesquisa, selecionamos apenas os estudos sobre EJA produzidos na área de Educação, que totalizaram 32 trabalhos. Na tabela 1 apresentamos a distribuição dos trabalhos por ano e suas temáticas específicas.

Tabela 1 -Distribuição da Produção Acadêmica sobre a EJAe EJA do Campo

\begin{tabular}{cccccccc}
\hline \multirow{2}{*}{ ANO } & \multicolumn{2}{c}{ DISSERTAÇÕES } & \multicolumn{2}{c}{ TESES } & \multicolumn{2}{c}{ TOTAL } & EJA/ \\
\cline { 2 - 7 } & EJA & $\begin{array}{c}\text { EJA/ } \\
\text { CAMPO }\end{array}$ & EJA & $\begin{array}{c}\text { EJA/ } \\
\text { CAMPO }\end{array}$ & EJA & $\begin{array}{c}\text { EJA/ } \\
\text { CAMPO }\end{array}$ & (\%) \\
\hline $\mathbf{2 0 0 6}$ & 125 & 2 & 19 & 2 & 144 & 4 & 2,7 \\
\hline $\mathbf{2 0 0 7}$ & 128 & 7 & 18 & 0 & 146 & 7 & 4,8 \\
\hline $\mathbf{2 0 0 8}$ & 156 & 4 & 29 & 1 & 185 & 5 & 2,7 \\
\hline $\mathbf{2 0 0 9}$ & 153 & 2 & 33 & 1 & 186 & 3 & 1,6 \\
\hline $\mathbf{2 0 1 0}$ & 176 & 4 & 35 & 3 & 211 & 7 & 3,3 \\
\hline $\mathbf{2 0 1 1}$ & 197 & 6 & 42 & 0 & 239 & 6 & 2,5 \\
\hline TOTAL & 935 & 25 & 176 & 7 & 1111 & 32 & 2,9 \\
\hline
\end{tabular}

Tendo em vista o número reduzido de pesquisas identificadas no Banco de Teses da CAPES, realizamos uma nova consulta diretamente aos Programas de Pós-Graduação em Educação das principais Instituições de Ensino Superior de Minas Gerais. Nesta etapa da pesquisa localizamos um total de 871 dissertações e teses sobre EJA publicadas, sendo que deste total de produções acadêmicas, apenas 8 dissertações abordavam a especificidade da EJA do Campo. A Tabela 2 ilustra a distribuição dessas produções acadêmicas por Instituição de Ensino Superior em Minas Gerais.

Tabela 2 - Distribuição das Dissertações por Instituições de Origem

\begin{tabular}{lccccl}
\hline \multirow{2}{*}{ INSTITUIÇÃO } & \multicolumn{5}{c}{ DISSERTAÇÕES } \\
\cline { 2 - 7 } & TOTAL & EJA & $\begin{array}{c}\text { EDUCAÇA } \\
\text { DO CAMPO }\end{array}$ & $\begin{array}{c}\text { EJA } \\
\text { CAMPO }\end{array}$ & $\begin{array}{l}\text { EJA/Campo } \\
\text { (\%do total) }\end{array}$ \\
\hline UFU & 186 & 6 & 8 & 1 & 0,53 \\
\hline PUC-MG & 123 & 2 & 9 & - & - \\
\hline UNIUBE & 59 & 2 & - & - & - \\
\hline UFJF & 156 & 5 & 4 & - & - \\
\hline UFMG & 304 & 35 & 12 & 3 & 0,98 \\
\hline UFSJ & 31 & 3 & 2 & 2 & 6,45 \\
\hline UFV & 12 & - & 2 & 1 & 8,33 \\
\hline TOTAL & 871 & 53 & 37 & 8 & 0,91 \\
\hline & & Fonte: Freitas (2013). & &
\end{tabular}

Assim, do conjunto das produções acadêmicas identificadas - 32 produções do Banco de Teses da CAPES e 08 produções das Instituições 
de Ensino Superior Mineiras - selecionamos 07 trabalhos que, abordando especificamente experiências de EJA do Campo, apresentavam contribuições importantes para nossas reflexões em torno da formação dos educadores de jovens e adultos do campo. No quadro 1 apresentamos a relação das produções selecionadas, com uma breve caracterização dos trabalhos.

Quadro 1 - Produções Acadêmicas Selecionadas

\begin{tabular}{|c|c|c|c|c|}
\hline Referência & $\begin{array}{c}\text { Experiencia } \\
\text { de EJA Investi- } \\
\text { gada }\end{array}$ & $\begin{array}{l}\text { Parcerias Envol- } \\
\text { vidas }\end{array}$ & $\begin{array}{l}\text { Sujeitos de } \\
\text { Pesquisa }\end{array}$ & $\begin{array}{l}\text { Área de Atua- } \\
\text { ção dos Edu- } \\
\text { cadores }\end{array}$ \\
\hline $\begin{array}{l}\text { Souza-Junior/ } \\
\text { UNEB/2006 }\end{array}$ & $\begin{array}{c}\text { Projeto de Edu- } \\
\text { cação e Capaci- } \\
\text { tação de Jovens } \\
\text { e Adultos em } \\
\text { Áreas de Refor- } \\
\text { ma Agrária na } \\
\text { Bahia }\end{array}$ & $\begin{array}{l}\text { UNEB, INCRA e } \\
\text { PRONERA }\end{array}$ & $\begin{array}{l}\text { Monitores/ } \\
\text { Educadores do } \\
\text { Projeto }\end{array}$ & $\begin{array}{l}\text { Educação } \\
\text { Não-Formal }\end{array}$ \\
\hline $\begin{array}{l}\text { Mazilão- } \\
\text {-Filho/2011 }\end{array}$ & $\begin{array}{c}\text { Método de } \\
\text { Alfabetização } \\
\text { "Sim, eu Posso" } \\
\text { no Ceará }\end{array}$ & $\begin{array}{c}\text { Secretaria de } \\
\text { Educação do } \\
\text { Estado do Ceará } \\
\text { e MST }\end{array}$ & $\begin{array}{l}\text { Educador do } \\
\text { Método de } \\
\text { Alfabetização } \\
\text { Investigado }\end{array}$ & $\begin{array}{l}\text { Educação } \\
\text { Não-Formal }\end{array}$ \\
\hline Silva/2008 & $\begin{array}{l}\text { Escolas Rurais } \\
\text { do Município } \\
\text { de Caeté }\end{array}$ & $\begin{array}{l}\text { Município de } \\
\text { Caeté }\end{array}$ & $\begin{array}{c}\text { Educadoras } \\
\text { das Escolas } \\
\text { Rurais }\end{array}$ & $\begin{array}{l}\text { Educação } \\
\text { Formal }\end{array}$ \\
\hline Souza/ 2008 & $\begin{array}{l}\text { Assentamento } \\
\text { do Golfo, no } \\
\text { Estado de } \\
\text { Sergipe }\end{array}$ & Não Especifica & $\begin{array}{l}\text { Educadoras do } \\
\text { Assentamento }\end{array}$ & $\begin{array}{l}\text { Educação } \\
\text { Formal }\end{array}$ \\
\hline Lucas/2009 & $\begin{array}{l}\text { Projeto de } \\
\text { Educação dos } \\
\text { posseiros do } \\
\text { Paraná }\end{array}$ & $\begin{array}{l}\text { Associação de } \\
\text { Famílias de Tra- } \\
\text { balhadores Ru- } \\
\text { rais de Pinhão } \\
\text { (AFATRUP), Ins- } \\
\text { tituto Ambiental } \\
\text { do Paraná, } \\
\text { Departamento } \\
\text { de Educação de } \\
\text { Jovens e Adultos, } \\
\text { da Secretaria } \\
\text { de Estado de } \\
\text { Educação e } \\
\text { Universidade de } \\
\text { Londrina }\end{array}$ & $\begin{array}{l}\text { Educadores do } \\
\text { Projeto }\end{array}$ & $\begin{array}{l}\text { Educação } \\
\text { Não-Formal }\end{array}$ \\
\hline Moura/2011 & $\begin{array}{c}\text { Programa PRO- } \\
\text { JOVEM Campo } \\
\text { - Saberes da } \\
\text { Terra em MG }\end{array}$ & $\begin{array}{l}\text { UFMG, MST, } \\
\text { MEC e Secre- } \\
\text { taria de Estado } \\
\text { de Educação de } \\
\text { Minas Gerais }\end{array}$ & $\begin{array}{c}\text { Educadores do } \\
\text { Programa }\end{array}$ & $\begin{array}{l}\text { Educação } \\
\text { Não-Formal }\end{array}$ \\
\hline $\begin{array}{l}\text { Vasconce- } \\
\text { los/2011 }\end{array}$ & $\begin{array}{c}\text { Escola Estadu- } \\
\text { al Localizada } \\
\text { em um assen- } \\
\text { tamento em } \\
\text { Tumiritinga/ } \\
\text { MG }\end{array}$ & Não Especifica & $\begin{array}{l}\text { Educadores de } \\
\text { Matemática } \\
\text { da Turma do } \\
2^{\circ} \text { Período da } \\
\text { Educação de } \\
\text { Jovens e Adul- } \\
\text { tos (EJA) do } \\
\text { Ensino Funda- } \\
\text { mental }\end{array}$ & $\begin{array}{l}\text { Educação } \\
\text { Formal }\end{array}$ \\
\hline
\end{tabular}

Fonte: Freitas (2013). 
Reflexão e Análise da Formação de Educadores de Jovens e Adultos do Campo

Conforme descrito no Quadro 1, as produções acadêmicas selecionadas analisam experiências educativas distintas que, presentes em diferentes estados da sociedade brasileira, revelam aspectos diversos sobre a EJA do campo. De início, um dos aspectos que as pesquisas nos revelam é o fato da EJA do Campo ocorrer, na maioria das experiências analisadas, no âmbito da educação não formal. Assim, dos sete estudos selecionados, quatro analisam situações educativas que se desenvolvem fora do espaço escolar. Neste aspecto, segundo Gohn (1997), enquanto a educação formal compreende o espaço das escolas, das instituições regulamentadas por lei, organizadas segundo diretrizes nacionais e garantindo certificação, a educação não formal compreende espaços educativos localizados em territórios que acompanham as trajetórias de vida dos grupos sociais locais por meio de processos interativos intencionais, localizados fora das escolas.

Nesse sentido, as pesquisas revelam uma dimensão importante no debate atual sobre a EJA em nossa sociedade, que é conhecer onde se realizam os processos educativos dos jovens e adultos do campo. Essa é uma questão importante, na medida em que nos auxilia a problematizar o objetivo da EJA e o público a que ela se destina. Assim, uma primeira questão é pensarmos qual educação queremos para os jovens e adultos do campo: uma educação conteudista, burocrática e homogeneizadora ou uma educação que contribui para mobilizar esses sujeitos para processos de transformação de suas realidades sociais? Essas são questões importantes que merecem uma atenção especial por parte dos sujeitos que debatem, atuam e constroem a EJA do Campo em nossa sociedade.

E nesse aspecto, cabe ressaltar que a EJA do Campo, devido a sua tendência de estar inserida majoritariamente no âmbito da educação não formal, também tem como característica marcante o fato de se desenvolver por meio de programas e/ou projetos que envolvem parcerias diversas na sua execução, a exemplo do Projeto de Educação e Capacitação de Jovens e Adultos em áreas de Reforma Agrária, realizado na Bahia (Souza-Junior, 2006), o Método de Alfabetização Sim, eu posso, realizado no Ceará (Mazilão-Filho, 2011), o Programa de Educação dos Posseiros do Paraná (Lucas, 2009) e o Programa Projovem Campo - Saberes da Terra, em Minas Gerais (Moura, 2011). Assim, outro aspecto importante revelado pela produção acadêmica analisada é a existência de parcerias diversas na execução das ações educativas da EJA do Campo. Essas parcerias, por sua vez, são consideradas como sendo uma das alternativas para o fortalecimento das ações de Educação de Jovens e Adultos. Vale destacar que essa dinâmica de parceria na condução das experiências de EJA do Campo não emerge em nenhuma das experiências de Educação de Jovens e Adultos que ocorrem no âmbito da educação formal que, segundo as produções acadêmicas analisadas, aparecem sempre sob a responsabilidade dos municípios (Silva, 2008) e/ou do Estado (Vasconcelos, 2011). 
Além disso, os estudos nos possibilitam algumas reflexões em torno dos riscos e desafios dos processos participativos na construção de políticas públicas, especificamente nos alertando sobre como as demandas e lutas dos movimentos sociais do campo podem ser apropriadas por outros segmentos da sociedade que, com interesses antagônicos, acabam por efetivar projetos, programas e/ou políticas que favorecem outro projeto de campo e de educação, distintos dos princípios que orientam o movimento da Educação do Campo.

Também os estudos de Vasconcelos (2011) e Silva (2008) revelam a presença de contradições nas práticas educativas das experiências de EJA do Campo analisadas, principalmente no tocante a reprodução de uma ideologia de oposição entre campo e cidade que, por sua vez, também se encontra expressa no currículo, manifestando tendências de reprodução de um sistema escolar rígido em contraposição ao discurso e intenção existentes de uma educação emancipatória. São indícios de que essas experiências ainda veiculam, mesmo que indiretamente, representações ideológicas e uma perspectiva dicotômica na qual o campo é concebido como lugar de atraso e a cidade como espaço privilegiado de desenvolvimento e prosperidade.

Em relação a essa visão de campo, cabe ressaltar que há mais de 16 anos o Movimento de Educação do Campo vem lutando pela superação dessa perspectiva ideológica, afirmando outra concepção de campo, de escola e de educação. Campo como espaço de vida, trabalho e produção de conhecimentos, reconhecendo a dignidade deste espaço e dos seus sujeitos, suas histórias, seus modos de vida e identidades culturais. Assim, conforme destacado pelo estudo de Silva (2008), a superação dessas velhas representações e ideologias ainda se mantém como um dos desafios da Educação do Campo na atualidade. Um desafio presente em municípios nos quais, conforme revelado pelo referido estudo, a Educação do Campo ainda não se constitui em política pública, situação também compartilhada em diversas outras realidades municipais.

Neste aspecto, é interessante destacar que o Programa de Estudos intitulado Cenários da Educação no Meio Rural de Minas Gerais (Silva, 2009), identificou que a maioria das Secretarias Municipais de Educação, por ocasião da pesquisa, desconhecia as Diretrizes Operacionais para a Educação Básica nas Escolas do Campo, aprovadas em 2002. O estudo também constatou, nos municípios mineiros pesquisados, a inexistência de iniciativas educacionais específicas para os sujeitos do campo, principalmente no tocante a EJA do Campo. Assim, se a aprovação das Diretrizes Operacionais para a Educação do Campo representou um avanço legal importante, ainda persiste na atualidade o desafio de sua implementação no cotidiano das escolas, assim como nas experiências de EJA do Campo.

Em relação aos estudos que analisam as experiências de EJA do Campo em outros estados brasileiros, um aspecto comum destacado 
Reflexão e Análise da Formação de Educadores de Jovens e Adultos do Campo

por eles é a importância do diálogo e envolvimento dos movimentos sociais e sindicais do campo nos processos de formação dos educadores de EJA do Campo. As pesquisas revelam, assim, nuances dos processos formativos que, assumindo a perspectiva dos estudos atuais sobre formação de professores, podem ser consideradas como constituídas de processos contínuos e permanentes de busca de articulação com o conjunto das vivências e experiências dos educadores (Nóvoa, 1995; Garcia, 1999; Popkewitz, 1995).

Apesar desta tendência identificada, os estudos também revelam a necessidade de existência de outros espaços de formação no qual os educadores possam, em articulação com suas experiências e práticas cotidianas, sistematizar e apropriar os saberes e conhecimentos necessários à função docente. Neste aspecto, a pesquisa de Souza (2008) ressalta a necessidade de reformulação dos cursos de formação de educadores do campo, frente à constatação de que a formação das educadoras pesquisadas não foi suficiente para desconstruir os (pré) conceitos em relação à visão de subordinação do campo à cidade. Assim, o estudo afirma a necessidade de uma formação específica do educador de jovens e adultos do campo, reiterando a constatação dos trabalhos de Popkewitz (1995), de que as políticas de formação de educadores têm se preocupado demasiadamente com uma aquisição de informações fragmentárias e orientadas para a prática, todavia sem favorecer processos de reflexão e o pensamento crítico diante da realidade experienciada.

Além disso, os estudos revelam que as experiências de EJA do Campo aglutinam uma diversidade de sujeitos sociais, como posseiros, agricultores familiares, assentados da reforma agrária, trabalhadores rurais, entre outros. Uma diversidade de jovens e adultos que vivem no e do campo, com culturas, histórias, práticas e experiências educativas também diversas. Reconhecer esta diversidade e incorporá-la no projeto político pedagógico das escolas do campo constitui, segundo Arroyo (2012), uma das marcas do movimento da Educação do Campo no seu propósito de luta e construção de outro projeto de sociedade e de campo. Especificamente, nas experiências analisadas, os sujeitos da EJA do Campo são, predominantemente, jovens e adultos que integram a luta pela terra. Assim, do conjunto de sete (7) experiências educativas de EJA do Campo que foram objeto das dissertações e teses analisadas, quatro (4) delas foram realizadas em áreas da reforma agrária.

Outro aspecto revelado pela produção acadêmica analisada é que, majoritariamente, as experiências de EJA do Campo pesquisadas foram desenvolvidas numa dinâmica de parceria envolvendo movimentos sociais e sindicais do campo, universidades e poder público. A única exceção foi a experiência analisada por Silva (2008), que constitui uma iniciativa de EJA do Campo realizada nos moldes convencionais da educação regular, sob a responsabilidade do município. Todavia, em relação às parcerias, os estudos revelam também que muitas destas que

566 Educação \& Realidade, Porto Alegre, v. 41, n. 2, p. 555-573, abr./jun. 2016. 
fornecem sustentação às experiências de EJA do Campo nem sempre ocorrem de maneira harmoniosa. Ao contrário, em muitas experiências são parcerias que refletem e explicitam as tensões e contradições próprias da relação entre sujeitos sociais diferentes, cujas lógicas e práticas são divergentes.

Especificamente em relação ao educador de jovens e adultos do campo, os estudos também revelam a existência, nas experiências analisadas, de diferentes sujeitos atuando na EJA do campo. Neste sentido, identificamos a presença de educadores envolvidos diretamente em processos de mobilizações e de lutas pela terra, que têm na própria vivência nos movimentos sociais o lócus de suas aprendizagens mais significativas. Educadores que, sem nenhum vínculo com os movimentos sociais e/ou sindicais do campo, apresentavam dificuldades no desenvolvimento de práticas pedagógicas orientadas para fortalecimento do protagonismo dos jovens e adultos do campo e que, a despeito dos processos de formação vivenciados, apresentavam dificuldades em romper com velhas representações, principalmente em relação ao campo e aos seus sujeitos. Os estudos indicam, ainda, situações nas quais educadores apresentavam dificuldades em suas práticas pedagógicas no estabelecimento de uma maior conexão entre a formação teórica recebida e a vivência no cotidiano da sala de aula de EJA.

O conjunto da produção acadêmica analisada revela, assim, indícios de que o educador de EJA do Campo que tem uma inserção social e política no contexto social em que atua - no caso das experiências analisadas, em movimentos sociais e sindicais do campo; mesmo não tendo recebido uma formação acadêmica específica, tende a desenvolver uma capacidade crítica que contribui significativamente para sua reflexão sobre essa realidade vivida, o papel da educação e o desenvolvimento de práticas pedagógicas emancipadoras. Ou seja, a inserção e/ou a experiência dos educadores em movimentos sociais tende a ser um diferencial no seu processo de (auto) formação, assim como na sua atuação docente. E neste aspecto, também podemos pressupor que a formação destes educadores de EJA do Campo não tem ocorrido apenas por acúmulo de cursos, conhecimentos e/ou técnicas, mas fundamentalmente pela capacidade destes educadores de agirem e refletirem criticamente sobre a realidade, numa dinâmica de reconstrução permanente da identidade pessoal (Nóvoa, 1995).

Nesta perspectiva, outro aspecto importante que emerge das análises dos estudos sobre as experiências de EJA do Campo é a tendência existente entre estes educadores de busca constante de conhecimentos e desenvolvimento de estratégias que possam lhes auxiliar na superação dos problemas vivenciados no cotidiano de suas práticas docentes. Assim, mobilizando conhecimentos e estratégias variadas - como diversificação dos recursos didáticos, intercâmbio e trocas com colegas, atividades de formação pedagógica, participação em seminários, entre 
outros, são educadores que buscam responder as demandas e os desafios enfrentados no cotidiano de suas salas de aula, numa perspectiva da autoformação.

A despeito desta tendência identificada, os estudos sobre as experiências de EJA do Campo também são convergentes na constatação da necessidade de maiores investimentos na formação dos educadores de EJA do Campo - tanto na perspectiva de uma formação inicial específica, quanto na formação continuada, a partir de processos que contribuam, entre outros, para uma melhor compreensão dos aportes teórico-metodológicos dessa modalidade de ensino. E, neste aspecto, torna-se importante destacar que no conjunto das experiências de EJA do Campo que foram analisadas, em cinco (5) delas os educadores não tiveram acesso a uma formação acadêmica mínima para atuação na Educação de Jovens e Adultos (Souza-Junior, 2006; Mazilão-Filho, 2011; Souza, 2008; Silva, 2008; Lucas, 2009). E esta não é uma tendência isolada. Ao contrário, ela reflete a situação histórica, presente em nossa sociedade, de descaso e marginalidade da EJA em relação às políticas educacionais e, especialmente, no tocante a formação de seus educadores (Di Pierro, 2010; Vóvio, 2010; Porcaro, 2011).

Essa condição de marginalidade da EJA também parece contribuir para ancorar representações construídas sobre a docência na Educação de Jovens e Adultos que, conforme explicitado no estudo de Silva (2008), sustentadas nas ideias de provisoriedade e complemento de renda, ancoram um sentido de bico. Também nesta perspectiva, o estudo de Moura (2011) evidencia que a grande maioria dos educadores selecionados para atuarem no Programa de EJA do Campo analisado não tinha vínculos com o campo, com entidades ou movimentos populares, tendo sido o ingresso no Programa motivado pela oportunidade do primeiro emprego ou de uma complementação salarial. Acrescentem-se, ainda, as condições de trabalho dos educadores como um dos fatores que contribui para esta desvalorização da EJA do campo. A maioria dos estudos revela que as condições de trabalho nas experiências analisadas eram bastante precárias, enfrentando os educadores dificuldades diversas, como ausência de material didático (cadernos para os educandos, livros complementares) e de infraestrutura física adequada (iluminação, espaços para as salas de aula); baixa remuneração; entre outros aspectos que indicam a ausência de investimentos mínimos para garantir as condições básicas necessárias ao trabalho do educador. São, portanto, condições, sentidos e representações sobre a EJA que revelam uma tendência histórica presente em nossa sociedade de marginalização da EJA, assim como da Educação do Campo.

Enfim, de uma maneira geral, as pesquisas analisadas revelam a existência de muitos desafios em relação à formação dos educadores de EJA do Campo, sinalizando que essa formação ainda é marcada pela ausência de ações de formação inicial e continuada dos educadores. Além 
disso, os estudos apontam indícios sobre a necessidade de reformulação dos cursos esporádicos de formação existentes, de modo que eles possam favorecer espaços sistemáticos de formação de educadores de jovens e adultos do campo, capazes de potencializarem processos de ação-reflexão-ação.

\section{Considerações Finais}

No presente artigo buscamos sistematizar, a partir de uma revisão da produção acadêmica nacional, um conjunto de reflexões e análises sobre a EJA do campo, especificamente os desafios e perspectivas enfrentados para a formação de seus educadores. Na realização desses propósitos, um primeiro aspecto que despertou nossa atenção foi em relação ao número das produções acadêmicas sobre a EJA do campo. Identificamos um número reduzido e pouco expressivo de pesquisas, principalmente quando comparado ao total dos estudos sobre a Educação de Jovens e Adultos: apenas 3\% do total das pesquisas identificadas abordavam a temática especifica da EJA do Campo. Portanto, um dos desafios atuais é superar esta lacuna teórica existente na produção acadêmica nacional, de maneira a avançar na produção de estudos e reflexões acadêmicas que possibilitem compreender melhor as diversas práticas educativas de jovens e adultos em curso na sociedade brasileira atual.

Outro aspecto que merece ser destacado é a tendência predominante das pesquisas de EJA do Campo em privilegiarem como temáticas de estudos os programas e/ou experiências de EJA do campo. Assim, a temática da formação de educadores na EJA do Campo ainda é incipiente e emerge de maneira secundarizada no conjunto das pesquisas analisadas. Destarte, da mesma forma que existe uma ausência de ações de formação de educadores da EJA - principalmente no contexto da Educação de Jovens e Adultos do Campo -, também existe uma carência de estudos sobre essa temática nas produções acadêmicas nacionais. Esses aspectos revelam, portanto, que a EJA do Campo, em especial a formação de seus educadores, parece estar ainda invisível no conjunto dos pesquisadores brasileiros.

Todavia, apesar do reduzido número de estudos sobre a formação de educadores de EJA do Campo, as pesquisas apresentam contribuições importantes, no sentido de revelarem que existe uma carência de educadores de EJA do Campo. Assim, os educadores das experiências analisadas não têm formação mínima para uma atuação na docência da Educação de Jovens e Adultos. Entretanto, eles são contratados porque não existem outros profissionais qualificados para a função. Os estudos revelam, ainda, que neste processo, vai sendo consolidada uma representação enviesada da EJA como uma modalidade de educação que não exige formação dos seus educadores, confirmando a afirmativa de Diniz-Pereira e Fonseca (2001) de que ser educador de jovens e adultos 
Reflexão e Análise da Formação de Educadores de Jovens e Adultos do Campo

não se constitui uma opção para a vida profissional, por ser considerado um trabalho temporário e de complementação de renda.

Essa constatação reafirma a importância de criação de cursos de formação específicos para esses educadores do campo, de modo a instrumentalizá-los sobre os conhecimentos necessários para essa área de atuação específica. Porcaro (2011), em sua pesquisa, também analisou essa necessidade de criação de cursos específicos para os educadores da EJA. Essa é uma questão, portanto, que precisa ser pautada junto aos órgãos competentes, considerando que a demanda por EJA é cada vez mais crescente e atual em nossa sociedade.

As pesquisas analisadas também revelaram, assim como o estudo de Porcaro (2011), que são os conhecimentos adquiridos na prática cotidiana que orientam o trabalho dos educadores, favorecendo assim práticas educativas inovadoras e mais próximas da realidade social dos educandos. Nesse aspecto, podemos identificar a presença de alguns educadores de EJA do Campo que buscam desenvolver um trabalho que dialoga com os princípios da Educação do Campo e da Educação Popular, nos quais a realidade social constitui o ponto de partida da práxis educativa. Entretanto, as pesquisas analisadas também revelaram a presença de educadores que se mostram acomodados e realizam um trabalho conteudista e homogeneizador, sem levar em conta as singularidades dos educandos e do meio social no qual se encontram. Assim, podemos afirmar que não existe uma concepção unânime da Educação do Campo por parte dos educadores e, reiterando as ideias de Molina (2009), reconhecemos a necessidade de ruptura com o modelo tradicional de formação de educadores do campo, para afirmação e garantia dos princípios fundamentais do movimento da Educação do Campo.

Uma dimensão importante a ser considerada, ainda sobre o conjunto das pesquisas analisadas, é que elas revelaram a importância dos movimentos sociais na construção da EJA do Campo e na formação dos educadores. Os movimentos sociais têm um potencial formativo para todos que deles participam, visto que o diálogo favorece um olhar crítico sobre a realidade. Todavia, apesar dos movimentos demandarem políticas e construírem experiências educativas originais, às vezes, no tensionamento com as forças do poder capitalista e confronto dos projetos políticos em disputa, eles não conseguem acompanhar as políticas, quando de sua efetivação. Assim, conforme revelam as pesquisas, os movimentos sociais têm sido protagonistas fundamentais no processo de construção da Educação do Campo e fator ímpar nas ações de formação dos educadores de jovens e adultos do campo. Entretanto, uma questão ainda se faz necessária: até onde vai o protagonismo dos movimentos sociais nas políticas de EJA do Campo? Essa é uma questão que merece atenção especial, indicando a necessidade de estudos sobre a potência e o lugar dos movimentos sociais na construção de políticas de EJA do Campo, especificamente para a formação dos seus educadores.

570 Educação \& Realidade, Porto Alegre, v. 41, n. 2, p. 555-573, abr./jun. 2016. 
Além da necessidade de uma política de formação de educadores de jovens e adultos do campo, é de fundamental importância a inserção das questões da EJA nos cursos de formação de educadores, como os cursos de Pedagogia e Licenciaturas, considerando que em algum momento de suas atividades profissionais, os educadores podem se envolver com essa modalidade de ensino. A formação específica e adequada dos profissionais da educação para uma atuação na EJA do Campo, bem como a valorização destes profissionais e a garantia de condições de trabalho adequadas tornam-se, portanto, condições para o reconhecimento e valorização dos diversos sujeitos sociais do campo. E, apesar de ser um direito conquistado na legislação brasileira, essa ainda permanece como uma bandeira atual de luta dos movimentos sociais e sindicais do campo.

Recebido em 16 de junho de 2014 Aprovado em 23 de maio de 2015

\section{Referências}

ANTUNES-ROCHA, Maria Izabel; MARTINS, Aracy Alves (Org.). Educação do Campo: desafios para a formação de professores. Belo Horizonte: Autêntica, 2009.

ARROYO, Miguel Gonzalez; CALDART, Roseli Salete; MOLINA, Mônica Castagna (Org.). Por uma Educação do Campo. Petrópolis: Vozes, 2004.

ARROYO, Miguel Gonzalez. A Educação Popular do Campo e a Realidade Camponesa. In: REUNIÃO ANUAL DA ANPED, 30, 2007, Caxambu. Anais... Caxambu, 2007.

ARROYO, Miguel Gonzalez. Diversidade. In: CALDART, Roseli Salete et al. (Org.). Dicionário da Educação do Campo. São Paulo: Expressão Popular, 2012. P. 231-238.

BATISTA, Maria do Socorro Xavier. A Educação Popular do Campo e a Realidade Camponesa. In: REUNIÃO ANUAL DA ANPED, 30, 2007, Caxambu. Anais... Caxambu, 2007.

DI PIERRO, Maria Clara. Balanço e Desafios das Políticas Públicas de Educação de Jovens e Adultos no Brasil. In: SOARES, Leôncio et al. (Org.). Convergências e Tensões no Campo da Formação e do Trabalho Docente. Belo Horizonte: Autêntica, 2010. P. 27-43.

DINIZ-PEREIRA, Júlio Emílio; FONSECA, Maria da Conceição Ferreira Reis. Identidade Docente e Formação de Educadores de Jovens e Adultos. Educação \& Realidade, Porto Alegre, v. 26, n. 2, p. 51-73, jul./dez. 2001.

FAZZI, José Luiz. Itinerários Formativos e Curriculares na Educação de Jovens e Adultos. 2007. Tese (Doutorado em Educação) - Universidade Federal de Minas Gerais, Belo Horizonte, 2007.

FERNANDES, Bernardo Mançano. Educação do Campo e Território Camponês no Brasil. In: SANTOS, Clarice Aparecida (Org.). Por uma Educação do Campo: campo, políticas públicas, educação. Brasília: MDA, 2008. P. 39-66.

FREITAS, Katia Pinheiro de. Formação de Educadores de Jovens e Adultos do Campo: produções do período 2006-2011. 2013. 157f. Dissertação (Mestrado em Educação) - Universidade Federal de Viçosa, Viçosa, 2013.

Educação \& Realidade, Porto Alegre, v. 41, n. 2, p. 555-573, abr./jun. 2016. 
Reflexão e Análise da Formação de Educadores de Jovens e Adultos do Campo

GARCIA, Carlos Marcelo. Formação de Professores: para uma mudança educativa. Porto: Porto Editora, 1999.

GOHN, Maria da Glória. Teoria dos Movimentos Sociais. São Paulo:Edições Loyola, 1997.

LUCAS, Karin Adriane Hugo. A Formação dos Educadores como Eixo do Desenvolvimento Curricular: o Projeto de Educação dos Posseiros do Paraná (PEPO). 2009. 218f. Tese (Doutorado em Educação) - Pontifícia Universidade Católica de São Paulo, São Paulo, 2009.

MAZILÃO-FILHO, Ageu Quintino. O Uso do Método de Alfabetização “Sim, Eu Posso" pelo MST no Ceará: o papel do monitor da turma. 2011. 157f. Dissertação (Mestrado em Educação) - Universidade Federal de São João del Rei, São João del Rei, 2011.

MENEZES NETO, Antônio Júlio de. Formação de Professores para a Educação do Campo: projetos sociais em disputa. In: ANTUNES-ROCHA, Maria Izabel; MARTINS, Aracy Alves (Org.). Educação do Campo: desafios para a formação de professores. Belo Horizonte: Autêntica Editora, 2009. P. 25-38.

MOLINA, Mônica Castagna. Educação do Campo: cultivando princípios, conceitos e práticas. Presença Pedagógica, Belo Horizonte, n. 88, jul./ago. 2009.

MOLINA, Mônica Castagna (Org.). Educação do Campo e Pesquisa II: questões para reflexão. Brasília: MDA/MEC, 2010.

MOURA, Tânia Maria de Melo. Formação de Educadores de Jovens e Adultos: realidade, desafios e perspectivas atuais. Práxis Educacional, Vitória da Conquista, v. 5, n. 7, p. 45-72, jul./dez. 2009.

MOURA, Regina Celi Alvarenga de. Pedagogia da Alternância: limites e perspectivas do Projovem Campo em Minas Gerais. 2011. 117f. Dissertação (Mestrado em Educação) - Universidade Federal de Viçosa, Viçosa, 2011.

MUNARIM, Antônio. Prefácio. In: LENZI, Lucia Helena Correa (Org.). Formação de Educadores em EJA no Campo: compartilhando saberes. Florianópolis: NUP/CED/UFSC, 2007.

NÓVOA, Antônio (Org.). Os Professores e a sua Formação. Lisboa: Dom Quixote, 1995.

PORCARO, Rosa Cristina. Caminhos e Desafios da Formação de Educadores de Jovens e Adultos. 2011. Tese (Doutorado em Educação) - Universidade Federal de Minas Gerais, Belo Horizonte, 2011.

POPKEWITZ, Tomáz. Profissionalização e Formação de Professores. In: NÓVOA, Antônio (Org.). Os Professores e a sua Formação. Lisboa: Dom Quixote, 1995. P. 35-50.

SANTOS, Clarice Aparecida dos (Org.). Por uma Educação do Campo: campo, políticas públicas, educação. Brasília: Incra/MDA, 2008.

SILVA, Giane Maria. Concepções de Leitura em Práticas de Letramento na Educação de Jovens e Adultos do Meio Rural. 2008. 186f. Dissertação (Mestrado em Educação) - Universidade Federal de Minas Gerais, Belo Horizonte, 2008.

SILVA, Lourdes Helena da. Cenários da Educação no Meio Rural de Minas Gerais. Curitiba: CRV, 2009.

SILVA, Lourdes Helena da; COSTA, Vânia Aparecida; ROSA, Walquíria Miranda. A Educação de Jovens e Adultos em Áreas de Reforma Agrária: desafios da formação de educadores do campo. Revista Brasileira de Educação, Rio de Janeiro, v. 16, n. 46, p. 49-166, jan./abr. 2011. 
SOUZA, Kelly Pereira de. Luta pela Terra, Luta pela Palavra: história de vida e formação de duas educadoras populares do campo. 2008. 173f. Dissertação (Mestrado em Educação) - Universidade Federal do Rio Grande do Norte, Natal, 2008.

SOUZA, Maria Antônia de. Educação do Campo: políticas, práticas pedagógicas e produção científica. Educação e Sociedade, Campinas, v. 29, n. 105, p. 1089-1111, set./dez. 2008. Disponível em:<http://www.cedes.unicamp.br>. Acesso em: 12 fev. 2011.

SOUZA-JUNIOR, Mauro Roque. Educação na Reforma Agrária: uma proposta extensionista da UNEB para o PRONERA. 2006. 149f. Dissertação (Mestrado em Educação e Contemporaneidade) - Universidade do Estado da Bahia, Salvador, 2006.

VARGAS, Maria Cristina; MANGGINI, Tiago. A Educação de Jovens e Adultos em movimento. In: LENZI, Lucia Helena; CORD, Denise (Org.). Formação de Educadores em EJA no Campo: compartilhando saberes. Florianópolis: NUP/CED/ UFSC, 2007. P. 151-164.

VASCONCELOS, Kyrleys Pereira. Um Estudo Sobre Práticas de Numeramento na Educação do Campo: tensões entre os universos do campo e da cidade na educação de jovens e adultos. 2011. 126f. Dissertação (Mestrado em Educação) Universidade Federal de Minas Gerais, Belo Horizonte, 2011.

VÓVIO, Cláudia Lemos. Formação de Educadores de Jovens e Adultos: a apropriação de saberes e práticas conectadas à docência. In: SOARES, Leôncio (Org.). Convergências e Tensões no Campo da Formação e do Trabalho Docente. Belo Horizonte: Autêntica, 2010. P. 70-77. (XV ENDIPE).

Katia Pinheiro Freitas é mestre pela Universidade Federal de Viçosa (2013), com de pesquisa na área de Formação de Professores. Foi bolsista do Observatório de Educação do Campo CAPES/INEP, no projeto em rede UFV/ UFSJ/UEMG (2011-2013); bolsista de Iniciação Científica do CNPq (20092010), e voluntária em diversos Projetos de Extensão da Universidade Federal de Viçosa (2007-2008)

E-mail: katia_mestrado@hotmail.com

Lourdes Helena da Silva é professora do Programa de Pós-Graduação em Educação da Universidade Federal de Viçosa. Doutora em Educação (Psicologia da Educação) pela PUC-SP (2000), possui Pós-Doutorado em Ciências da Educação pela Universidade de Lisboa (2008) e Estagio Senior, como Visiting Scholar, na Universidade da Califórnia de Los Angeles (2014). Com experiência na área de Educação, com ênfase em Educação do Campo, atua principalmente nos seguintes temas: educação do campo, pedagogia da alternância, educação de jovens e adultos do campo, agroecologia e representações sociais.

E-mail: lhsilva@ufv.br 